\title{
AS SEMENTES CRIOULAS NA AGRICULTURA TRADICIONAL E SUA IMPORTÂNCIA PARA A AGROBIODIVERSIDADE
}

Victor Augusto de Oliveira Meira ${ }^{1}$

\section{Resumo:}

O objetivo deste trabalho é analisar a questão do uso de sementes crioulas como medida de conservação da agrobiodiversidade e a necessidade de políticas públicas que mantenham o agricultor em sua terra e aplicando seus saberes agrícolas tradicionais. Será analisada a legislação nacional sobre sementes e cultivares, seu impacto na agricultura tradicional e a relação entre as sementes crioulas, que dependem de conhecimentos tradicionais associados, com o mercado nacional de sementes. Conclui-se pela importância de políticas públicas de proteção dos saberes agrícolas tradicionais, da segurança alimentar e da biodiversidade. A metodologia utilizada é a revisão bibliográfica e análise legislativa.

Palavras-chave:

Propriedade Intelectual; Segurança Alimentar; Agrobiodiversidade; Sementes Crioulas; Acesso a Recursos Genéticos e aos Conhecimentos Tradicionais

\section{CREOLE SEEDS IN TRADITIONAL AGRICULTURE AND ITS IMPORTANCE FOR AGROBIODIVERSITY}

\begin{abstract}
:
The objective of this work is to analyze the issue of the native seeds as a measure of conservation of agrobiodiversity and need for public policies that keep the farmer on his land and apply his traditional agricultural knowledge. The national legislation on seeds and cultivars, their impact on traditional agriculture and the relationship between creole seeds, which depends on general knowledge associated with the national seed market, will be analyzed. The conclusion goes for the importance of public policies in the protection of traditional agricultural knowledge, food security and biodiversity. The methodology used is literature review and legislative analysis.

Keywords:

Intellectual Property; Food Security; Agrobiodiversity; Native Seeds; Access to Genetic Resources and Traditional Knowledge
\end{abstract}

\section{INTRODUÇÃO}

O presente trabalho parte do pressuposto de que há o direito fundamental à alimentação socialmente construído como consequência do constante combate à fome

\footnotetext{
${ }^{1}$ Mestrando em Direito, Políticas Públicas e Desenvolvimento Regional no Programa de Pós-Graduação em Direito do Centro Universitário do Pará (CESUPA). Pós Graduado em Direito Agroambiental pelo Centro Universitário do Pará (CESUPA). Advogado. victor_meira@hotmail.com.
} 
evidenciado por um processo dinâmico de inserção social do indivíduo no campo atrelado ao uso efetivo da terra, que lhe confere dignidade.

É preciso destacar que a efetivação da segurança alimentar não implica no abandono de técnicas modernas de agricultura e pecuária ou no impedimento do crescimento da agroindústria, que é um dos pilares mais sólidos da economia brasileira, impraticável sem o desenvolvimento que gere mecanismos efetivos de produção, trabalho e tributos ao Estado. Não está se propondo o retrocesso tecnológico, mas analisando seus limites e alternativas para que se permita uma verdadeira justiça social no meio rural.

De natureza intrinsecamente multidisciplinar, no caso aqui tratado, o das sementes crioulas e do acesso à biodiversidade agrária (agrobiodiversidade), a questão ambiental surge nítida porque envolvidos a utilização de recursos fitogenéticos, a manipulação e a liberação de organismos modificados geneticamente no meio ambiente para produção e consumo humano e a apropriação privada da vida (patentes biotecnológicas) em contraste com as práticas milenares da agricultura tradicional que envolvem práticas de cultivo, o controle biológico de pragas e doenças (pesticidas naturais), a seleção, o desenvolvimento e o melhoramento de variedades localmente adaptadas, a manutenção da fertilidade do solo.

Estes tópicos, todavia, ultrapassam preocupações exclusivamente ambientais e imbricam-se em assuntos como a situação de desenvolvimento dos países, especialmente os dotados de maior biodiversidade; o interesse comercial na utilização de recursos fitogenéticos para a geração de sementes patenteadas; o acesso a estes recursos; o conhecimento tradicional associado à agrobiodiversidade detido por comunidades locais de agricultores; a repartição de benefícios entre os fornecedores de recursos e conhecimentos e os que deles fazem uso.

Destarte, tem-se uma indústria transnacional extremamente organizada, com vínculos e ramificações em diversos setores da economia, utilizando pacotes tecnológicos, obrigando agricultores de diversos países (cujos governos normalmente estimulam o modelo do agronegócio expansivo), a utilizarem-se do desenvolvimento tecnológico por eles patenteado, o que suscita uma situação de extrema dependência, eis os agricultores perdem a soberania e a escolha sobre como será feito o cultivo e a comercialização dos produtos provenientes das safras agrícolas prejudicando, a longo prazo, os consumidores, que serão submetidos a uma dieta pobre e homogênea em nutrientes. 
Em vista desse panorama fático, procurou-se investigar a realidade jurídica do mercado de sementes e a inserção dos agricultores tradicionais (ou locais) nesta ordem jurídica e econômica, bem como sua importância para a conservação da biodiversidade.

Em um primeiro momento se inicia a abordagem do trabalho pela exposição do conceito de semente crioula, agricultura tradicional e agrobiodiversidade. Após, será realizada análise da legislação nacional sobre sementes e cultivares, seu impacto na agricultura tradicional e no uso das sementes crioulas, entendendo-as como base dos sistemas agrícolas locais.

A finalidade deste trabalho é demonstrar a importância e o papel secundário que, infelizmente, a agricultura tradicional e seus aspectos socioambientais tem tido na elaboração de políticas públicas de segurança alimentar e reforma agrária pois, de um lado, uma parcela importante dos agricultores e de suas organizações não dispõe de informações sobre as ameaças que hoje pesam sobre o direito de livre uso da biodiversidade. De outro, as lideranças do agronegócio desfrutam atualmente de notável capacidade de articulação e pressão junto aos poderes legislativo e executivo, e têm avançado a passos largos na promoção de seus interesses políticos e econômicos.

A metodologia utilizada para o fim de alcançar os objetivos apresentados é a revisão bibliográfica e a análise da legislação pertinente ao tema.

\section{CONHECIMENTO TRADICIONAL ASSOCIADO AGROBIODIVERSIDADE: O DIREITO DOS AGRICULTORES}

A ciência moderna tem sido utilizada como justificativa para a grande utilização de biotecnologia no campo da pesquisa agronômica, na produção de sementes transgênicas, protegidas por um arcabouço jurídico de propriedade intelectual. O argumento principal envolve a questão do conhecimento científico à elas incorporado, que geraria uma maior produtividade, necessária para a alimentação do crescente número da população humana.

Tal argumento é parcialmente questionável principalmente porque omite o papel dos agricultores tradicionais, que utilizam o conhecimento tradicional associado à agrobiodiversidade para o melhoramento natural das mudas e são uma alternativa viável à utilização em larga escala de biotecnologias que necessitam de agrotóxicos e vinculam o agricultor às mesmas empresas, que monopolizam o mercado alimentar mundial. A agroecologia não apenas encontra forte apoio na evidência empírica, mas também responde 
aos valores de sustentabilidade ecológica e da justiça social (PEREIRA, DAL SOGLIO, 2020)

É importante que se questione o status quo constantemente incutido pela mídia no senso comum de que somente o agronegócio industrial é capaz de fornecer alimentos de qualidade e com segurança alimentar no mercado. A crítica do uso intensivo ao uso de engenharia genética associadas a um sistema de patentes que exclui o conhecimento tradicional das populações de agricultores dos países desenvolvidos é válida e as alternativas que buscam a valorização do uso de sementes tradicionais e orgânicas tem se demonstrado necessária para a manutenção de um agroecossistema apto a gerar frutos para as outras gerações que ainda irão utiliza-lo. Afirma Lacey (2000, p. 53):

Criticar a biotecnologia parece beirar a blasfêmia, uma oposição ao desdobrar do futuro e à própria ciência. Busca-se com freqüência a legitimação do desenvolvimento e emprego de sementes TG na autoridade e prestígio da ciência e com isto espera-se silenciar todos os críticos. Contrariando essa postura, pode-se argumentar que a ciência não autoriza tal legitimação, e não coloca barreiras à exploração de formas alternativas de agricultura que estejam mais em sintonia com a luta por justiça social.

O desenvolvimento científico-tecnológico apresenta-se, hodiernamente, como um ramo da atividade econômica cujo domínio e exercício pertencem a poucos atores: os que conseguem transformar seus conhecimentos em direitos patrimoniais. Nessa conjuntura, sendo o risco inerente à atividade empresarial e compartilhado com toda a sociedade, os direitos intelectuais sobre a biotecnologia são resultantes da possibilidade de apropriação da vida por meio dos recursos genéticos da agrobiodiversidade e seu uso no desenvolvimento de novos produtos e processos biotecnológicos.

O Direito intelectual é utilizado enquanto estratégia para a consecução de prioridades e exclusividades sobre bens encontrados na natureza, a partir de institutos jurídicos como as patentes. A racionalidade econômico-tecnológica determina os rumos do desenvolvimento tecnológico dos modelos agrícolas de produção e das formas de comércio, distribuição e consumo dos produtos, implicando na privatização de racionalidades, saberes, conhecimentos, modelos produtivos, práticas comerciais e consumeristas que não se coadunam premissas constitucionais de proteção à diversidade biológica e cultural (GASPARINI, 2014).

Destarte, a homogeneização de práticas e produtos, por intermédio dos mercados e do consumo, incrementa os riscos socioambientais daqueles que se guiam por racionalidades 
alternativas, fato que remete à necessidade de estimulo a alternativas que englobem sujeitos excluídos do processo predominante.

Isto posto, é necessário buscar o reequilíbrio das forças dos atores envolvidos nesse jogo, garantindo-se, por meio de políticas públicas efetivas, os direitos dos agricultores, dos movimentos sociais e da coletividade relacionados à democracia participativa e ao pluralismo jurídico comunitário, bem como a segurança dos Estados-nação no que se refere à soberania e autonomia alimentar.

O lobby das empresas de biotecnologia transnacionais fez com que o Brasil reformulasse seu quadro regulatório para o setor agroalimentar, propriedade intelectual para biotecnologias e sementes, e acesso e controle à biodiversidade, num processo que gerou debate entre os setores empresariais e de pesquisa públicos e privados atuantes neste campo. Ocorreu a modificação do status dos recursos genéticos que, de uma condição de bens livres (encontrados na natureza) e sem valor econômico, passaram a ter uma condição de bens privados de alto valor, dada sua importância no processo produtivo dos mais variados itens de consumo (PESSANHA, 2002).

A percepção pública dos riscos e incertezas envolvidos na aplicação das novas biotecnologias ao sistema agroalimentar gerou a judicialização das questões envolvendo pesquisa e tecnologia na área. A positivação dos direitos envolvendo a produção, comercialização de sementes e grãos transgênicos, demonstra a magnitude dos conflitos de interesses em torno dos recursos genéticos, principalmente pelos riscos envolvendo a aplicação da engenharia genética ao sistema agroalimentar e seus efeitos sobre o meio ambiente.

Tendo e vista tais problemas, cresce a preocupação com a preservação da agrobiodiversidade, tendo esta se tornado um compromisso para o futuro, ${ }^{2}$ destacando-se o papel dos agricultores tradicionais na sua conservação. Importante observar que os agricultores tradicionais, que utilizam a terra para subsistência em regime de uso familiar, onde o conhecimento é passado de geração em geração, se encaixam no conceito legal de comunidade tradicional.

O conhecimento tradicional é explicado por Santilli (2005, p.135-136) como aqueles desenvolvidos a partir de "atividades e práticas coletivamente desenvolvidas na floresta" e são 2 Disponível em $\underline{\text { http://www.mda.gov.br/sitemda/noticias/preservar-agrobiodiversidade-\%C3\%A9-um- }}$
compromisso-com-o-futuro-0. Acesso em 02 de fev. 2021 . 
os responsáveis pela conservação da diversidade biológica de nossos ecossistemas, principalmente das florestas tropicais. A renomada autora inclui a necessária contribuição da agricultura tradicional para a manutenção do equilíbrio dos agroecossistemas, ao desenvolverem "os mais diversos conhecimentos sobre plantas domesticadas e cultivadas, bem como práticas de manejo de ecossistemas cultivados".

Os agricultores são importantes, pois desenvolvem diversos conhecimentos sobre plantas domesticadas e cultivadas (mecanismos de seleção e melhoramento genético, domesticação e intercâmbio de sementes que asseguram a variabilidade genética das plantas cultivada), bem como práticas de manejo de ecossistemas cultivados (SANTILLI, 2009).

Desta forma, a legislação e as políticas de conservação da diversidade biológica agrícola não podem deixar de reconhecer e valorizar o papel dos agricultores no manejo da diversidade fitogenética, promovendo as suas práticas e sistemas agrícola, pois sem esta não existe uma produção sustentável, que dure para o futuro. Em uma lógica de desenvolvimento sustentável, é preciso abandonar o sistema de mecanização do meio ambiente (Revolução Verde), de uso insumos químicos, e utilizar da diversidade ambiental. Tal procedimento se adequa muito bem na escala de uma propriedade familiar.

A necessidade de um regime sui generis para a proteção do conhecimento tradicional (no qual se incluiu a agricultura tradicional, praticada por famílias que utilizam as sementes crioulas) surge como meio de defesa das comunidades tradicionais. Pensa-se em uma proteção aos direitos comunitários sobre o conhecimento tradicional coletivo de grupos locais (agricultores, extrativistas, quilombolas) e indígenas que se diferencie do sistema de patentes da propriedade intelectual, eis que este é moldado para a proteção de interesses apenas econômicos, que tenham aplicação industrial (WANDSCHEER, 2004).

Os direitos intelectuais coletivos estariam, a priori, restritos à proteção dentro de cada nação que instituísse o regime de proteção sui generis. Contudo, seria o caso de um sistema institucionalmente válido, capaz de obrigar todos os envolvidos.

O sistema de patentes permite que indivíduos e empresas se apropriem da biodiversidade e dos conhecimentos das comunidades locais e populações tradicionais, mas não confere qualquer proteção ou benefício aos detentores de tais conhecimentos. As tentativas de adaptação do sistema desconsideram as próprias características e contextos culturais em que são produzidos os conhecimentos tradicionais e a importância da agricultura tradicional para a proteção da biodiversidade. 
A propriedade intelectual parte do pressuposto de direitos individuais pautados em critérios de inovação e utilidade industrial, pelo que seus titulares gozam de prerrogativas próprias de direitos reais. Afirma Santilli (2005, p. 149):

O conceito de propriedade - o direito do proprietário de usar, gozar e dispor da coisa, e de reavê-la do poder de quem quer que injustamente a possua ou detenha - é excessivamente estreito e limitado para abranger a complexidade dos processos que geram a inovação, a criatividade e a inventividade nos contextos culturais em que vivem povos indígenas, quilombolas e populações tradicionais. No Direito Ocidental, a propriedade - tanto sobre bens materiais quanto imateriais - é um direito essencialmente individual, e de conteúdo fortemente econômico e patrimonial, e, ainda quando se trata de propriedade coletiva ou condominial, cada co-titular do direito é plenamente identificável. Os processos inventivos e criativos de tais populações são, por essência, coletivos, e a utilização das informações, idéias e recursos gerados a partir de tais processos é amplamente compartilhado, e, portanto, a concepção de um direito de propriedade - pertencente a um indivíduo ou a alguns indivíduos determinados - é estranha e contrária aos próprios valores e concepções que regem a vida coletiva em tais sociedades. Por tal razão, é que se defende a adoção do conceito de "direitos intelectuais coletivos" (ou comunitários), para excluir a propriedade, devido ao seu caráter exclusivista, monopolístico e individualista.

É importante salientar a impossibilidade de se definir um marco temporal de vigência para direitos intelectuais sobre conhecimentos tradicionais, tais como uma patente, pois sua origem é indefinida no tempo e sua forma de transmissão, predominantemente oral, impede que se defina a geração originária do conhecimento.

Destarte, o monopólio conferido pelos direitos de propriedade intelectual contraria também a essência do processo de geração de conhecimentos tradicionais, eis que para este é imprescindível a liberdade de troca de sementes e informações entre as comunidades locais, de forma solidária. É perceptível a incompatibilidade entre um modelo de troca e escambo solidário e um modelo formal de outorga de direitos individuais sobre bens encontrados na própria natureza. Os benefícios são distintos para os integrantes da relação. É o que leciona Santilli (2005, p. 148):

[...] o sistema de patentes torna reservado um conhecimento que era compartilhado de maneira diversa, seja por especialização local, seja por livre circulação de idéias e informações. O sistema de patentes prejudica o modo como se produzem e usam os conhecimentos tradicionais, e não é possível se usar para proteger os conhecimentos tradicionais os mesmos mecanismos que protegem a inovação nos países industrializados, sob pena de destruir o sistema que os produz e matar o que se queria conservar. Afinal, o que é "tradicional" no conhecimento tradicional não é sua antigüidade, mas o modo como ele é adquirido e usado [...]

É através da propriedade intelectual que as maiores empresas de biotecnologia alimentar atualmente exercem controle sobre a produção agrícola em diversos países, 
principalmente os países em desenvolvimento na América Latina e Ásia, exercendo forte influência política e econômica sobre os seus governos, em uma biopolítica agressiva, constituindo os chamados impérios alimentares (GASPARINI, 2014).

No contexto contemporâneo da Revolução Biotecnológica, marcado pela atuação biopolítica dos Impérios Alimentares representados pelas empresas transnacionais de biotecnologia, as populações tradicionais são impingidas a cultivar determinados produtos, o que implica em mudanças de seus hábitos de produção e consumo, como no caso dos transgênicos. Trata-se de uma utilização perversa do conhecimento científico.

Para Wandscheer (2004, p.80) o conhecimento científico não está isento de valores, não é neutro, mas o desenvolvimento econômico pós revolução industrial direcionou este conhecimento para os interesses relacionados com o mercado, sendo que esta associação influenciou fortemente o direito positivo, dando origem ao sistema de patentes.

Em razão das considerações anteriores, pode-se afirmar que a atual conjuntura é um reflexo do histórico processo de apropriação da vida, proporcionado pelo ordenamento jurídico (PESSANHA, 2002). Historicamente, as sementes eram um bem comum, partilhado entre povos camponeses, comunidades tradicionais e povos indígenas. Não possuíam restrições ao uso, nem benefícios econômicos a determinados grupos. Mesmo antes do processo de globalização da economia e das informações, os recursos genéticos eram considerados patrimônio da humanidade, isto permeou o teor dos tratados internacionais sobre o gênero, firmando-se os conceitos acerca dos direitos dos agricultores sobre os recursos genéticos.

Posteriormente, as empresas transnacionais de biotecnologia, dedicadas às sementes e aos insumos e que, portanto, necessitam da apropriação desses recursos, visto que estes são matéria prima para seus produtos, se organizaram para que fossem reconhecidos os direitos dos obtentores, sendo criada a União Internacional de Proteção aos Direitos de Obtentor sobre Variedades Vegetais (UPOV), as chamadas cultivares. Nas palavras de Santilli (2009, p. 21) a descrição desse processo de apropriação:

$\mathrm{O}$ processo de cercamento, porém, se deu de forma célere e agressiva, desde as últimas décadas do século XX. Forçados pela Organização Mundial do Comércio e instrumentalizado por outra organização internacional chamada Upov (União para a Proteção das Obtenções Vegetais), os países foram legislando, cercando, obstruindo os conhecimentos dos agricultores e das propriedades tradicionais a tal ponto que as sementes passaram a ser propriedade privada de uns, excluídos todos os outros. Assim como a terra, as sementes perdiam sua natureza e se transformavam em 
mercadorias acessíveis apenas pelo contrato, perdida a generosidade da dádiva e entregue ao interesse mais mesquinho de um proprietário individual.

Após a Revolução Biotecnológica, ocorrida na segunda metade do século XX, tal processo de apropriação se intensificou, sendo que, atualmente, as atividades de biotecnologia tem suas pesquisas e produtos protegidos pelas patentes do sistema da Organização Mundial da Propriedade Intelectual (OMPI) e Organização Mundial do Comércio (OMC). Dessa forma, atualmente, a engenharia genética é um processo gradativo de domínio e manipulação da vida, mercantilizada e protegida pela propriedade intelectual. Sobre o tema, leciona Pessanha (2002, p. 83):

O caráter de bem público da informação genética veiculada pelas sementes faz com
que, por si só, os mecanismos de mercado não sejam capazes de garantir a total
apropriação e o retorno remunerado da atividade inventiva de melhoramento de
sementes. No início do século 20, quando o mercado de sementes se encontrava em
formação, já se verificavam problemas quanto à apropriação privada dos recursos
genéticos e das variedades lançadas no mercado. A semente se tornou uma
mercadoria paulatinamente, por meio de variáveis técnicas, com o desenvolvimento
de hibridação, que rompe a identidade entre a semente para plantio e o grão colhido,
e forjando a separação entre o agricultor e o produtor de sementes; e por força de
mecanismos institucionais e instrumentos jurídicos legalmente sancionados - por
meio da criação de sistemas de direitos de propriedade intelectual, que
possibilitaram a apropriação privada de variedades de alto rendimento.

De acordo com Santilli (2009, p. 242), essa apropriação torna os recursos genéticos e conhecimentos tradicionais em commodities ou mercadorias, subvertendo a própria lógica de geração e compartilhamento dos recursos e saberes das comunidades locais. Mesmo observado pela ótica contratual individualista do liberalismo, percebe-se que é necessária a repartição do benefício gerado, mesmo que seja como à retribuição pelo trabalho prestado, pois é fruto de observação, esforço e acumulação do conhecimento tradicional voltado para a aplicação de técnica, e portanto, sujeitos à uma contraprestação.

A justa repartição dos benefícios provenientes do uso sustentável destes recursos (tanto entre nações como entre usuários), assim como a garantia de existência e manutenção dos direitos coletivos dos povos indígenas e tradicionais habitantes das áreas mais ricas em biodiversidade também passaram a serem assuntos correntes quando a questão da conservação e uso da biodiversidade é abordada, em um contexto de aplicação da Convenção de Diversidade Biológica, ratificada pelo Brasil.

O monopólio praticado pelas transnacionais no mercado agrícola brasileiro gera a uniformidade genética, que leva à perda de variedades e à vulnerabilidade das plantas às pragas e doenças. Para se ter uma ideia da magnitude do problema: os povos pré-históricos 
alimentavam-se de mais de 1.500 espécies de plantas e pelo menos 500 dessas espécies e variedades têm sido cultivadas ao longo da história. Hoje, a alimentação está baseada em 233 apenas 30 vegetais cultivados e, desses, trigo, arroz, milho e soja representam mais de $85 \%$ do consumo de grãos (GASPARINI, 2014).

Grandes problemas são oriundos desta monopolização das patentes e sua concentração nas mãos das empresas que atuam na seara do agronegócio internacional. Destaca-se, além da insegurança alimentar causada pelo foco apenas nas variedades destinadas à exportação, e a possível aculturação dos povos e comunidades tradicionais, a notável situação de dependência tecnológica e econômica, pois a produção agrária fica presa a um sistema que não gera desenvolvimento ao país produtor, agravando desigualdades sociais e os problemas ambientais.

Nesse sentido, o uso (pelos agricultores) de produtos patenteados implica na aquisição, junto com a semente, de um "pacote tecnológico" (que consiste nos insumos necessários para que a semente patenteada germine), provocando a falta de sustentabilidade nos agrossistemas e na economia familiar, e a aculturação dos agricultores camponeses, que sempre guardaram, trocaram e reservaram sementes para os cultivos posteriores, gerando um conhecimento ligado à prática, no manejo dos recursos naturais.

Percebe-se que este modelo de utilização da terra, através da apropriação genética de plantas, animais e seus componentes implica na perda do controle sobre os recursos que tradicionalmente os camponeses e as comunidades tradicionais têm usado o que pode levar, futuramente, a novas formas de controle (e dependência) sobre as nações.

A escravização do agricultor pelo mercado internacional é clara. A industrialização do campo levou à perda de liberdade e criatividade dos agricultores que passaram a ser consumidores de técnicas de produção. Essas técnicas não se baseiam em considerações ecológicas, pois são forçadas, pelas conveniências do mercado, a voltar-se para tal ou tal mercadoria. Com isso, os agricultores já não cultivam aquilo que é mais indicado para determinado tipo de terra ou aquilo de que as pessoas necessitam, mas apenas o que o mercado dita.

A ação das empresas transnacionais é norteada pela política do fato consumado na introdução de seus produtos, através de práticas como a distribuição ilegal de sementes, a contaminação biológica de lavouras convencionais, a pressão sobre os agricultores para a adoção das sementes transgênicas e dos produtos químicos agrícolas a ela associados 
(gerando um problema aos agricultores que são vítimas da venda casada) e a influência direta sobre o poder público, na deliberação sobre a liberação de organismos geneticamente modificados. Afirma Maniglia (2009, p.246):

\begin{abstract}
[...] as práticas da Revolução Verde são repetidas, diuturnamente, no Brasil, gica do imediatismo e nas falsas seguranças afirmadas pelos grandes conglomerados multinacionais, que tornam seus compradores eternos dependentes da utilização de produtos químicos e, agora, das sementes, o que resulta na compra casada em que, comumente, os dois produtos (semente e herbicida) são oriundos da mesma empresa - o que, certamente, provoca a dependência econômica do produtor para com a mesma empresa, gerando os cartéis que impõem seus preços aos agricultores, os quais, na impossibilidade de manter seus débitos em dia ou sem a alternativa de preços, acabam por perder suas terras para essas indústrias ou para os grandes grupos econômicos. Nascem assim, também, a miséria, a pobreza, a fome e o êxodo rural.
\end{abstract}

Outro método é a compra sistemática de empresas de sementes e a cooptação de cooperativas para sua distribuição, de forma que são colocadas à venda apenas a semente com a qual terão mais lucro, dominando a cadeia agroalimentar desde a produção de sementes, agroquímicos e agrotóxicos até a parte de logística, transporte e exportação. Isso é o que se chama de dominação alimentar, eis que os agricultores são submetidos aos interesses dessas transnacionais. Isso é um problema grave para um país que quer ter soberania alimentar e condições melhores de produção para garantir alimentos de qualidade à população, eis que as necessidades de mercado de poucas empresas acabam por influenciar na diversidade biológica do alimento que chega à mesa da população (GASPARINI, 2014).

Desta forma, percebe-se a incapacidade do sistema de propriedade intelectual internacional em incluir os direitos de agricultores tradicionais e o conhecimento que eles detém sobre o manejo de recursos agroambientais. Entendidas por Santilli (2009, p.132) como "todo material de propagação vegetal que encerra em si a vida de uma planta" as sementes ocupam papel especial na discussão sobre segurança e autossuficiência alimentar, pois são a base da agrobiodiversidade e de qualquer sistema agrícola, determinando o modelo a ser adotado.

Daí deriva-se a importância de uma legislação que seja inclusiva, que promova não apenas interesses das empresas rurais, mas dos agricultores tradicionais, que utilizam a terra de maneira sustentável com base em uma agricultura familiar e, assim, permitindo a diversidade alimentar. A Lei de Sementes brasileira, em que pese haverem brechas que 
beneficiam estes agricultores, ainda precisa de ajustes, de forma que as políticas públicas nela baseadas permitam maior autossuficiência para os agricultores familiares.

\section{O DIREITO DOS AGRICULTORES DE GUARDAR, TROCAR, USAR E VENDER AS SEMENTES CRIOULAS}

Nos primórdios da civilização, o surgimento da agricultura causou grande impacto social, cultural e ambiental, permitindo que o ser humano, que outrora se integrava em grupos de coletores e caçadores, que viviam de plantas silvestres, da caça e da pesca, passasse a controlar quando, como e onde as plantas seriam cultivadas e os animais cultivados, através da observação empírica, seleção e cultivo das daquelas que melhor se adaptavam e produziam mais, para fins medicinais, religiosos e, principalmente, alimentares (SANTILLI, 2009).

Surgindo em climas favoráveis, quentes e temperados, nas regiões montanhosas, a agricultura se espalhou pelo mundo em virtude da migração humana, sendo a atividade humana mais próxima da natureza pois é, ainda, a fonte primordial de energia, obtida através dos alimentos que gera. Para Santilli (2009, p.37) a "revolução agrícola neolítica", que ocorreu entre dez e doze mil anos atrás, contribuiu para o modo de vida sedentário, permitindo um aumento populacional de cinco para cinquenta milhões em um intervalo de cinco mil anos.

As primeiras plantas cultivadas foram levadas e trazidas dentre as regiões, se adaptando e sendo selecionadas naturalmente, por processo biológico (conforme as teses biológicas do Evolucionismo), e também pelos processos simples dos agricultores (melhoramento tradicional). Nesse contexto surgiram as sementes tradicionais ou crioulas, que se adaptaram ao solo, ao clima e às condições peculiares dessas regiões, sendo conhecidas, cultivadas e armazenadas pelos agricultores, camponeses e povos tradicionais.

A Lei de Sementes (Lei n. 10.711/2003), no inciso XVI de seu artigo $2^{\circ}$, apresenta uma definição legal desse tipo de semente:

XVI - cultivar local, tradicional ou crioula: variedade desenvolvida, adaptada ou produzida por agricultores familiares, assentados da reforma agrária ou indígenas, com características fenotípicas bem determinadas e reconhecidas pelas respectivas comunidades e que, a critério do Mapa, considerados também os descritores socioculturais e ambientais, não se caracterizem como substancialmente semelhantes às cultivares comerciais; 
Observando a agricultura como um mecanismo inventivo humano em constante evolução, pode-se afirmar que os agricultores foram os primeiros observadores empíricos a manejar recursos naturais em uma atividade inventiva humana. Seu contato direto com as plantas e sua observação da natureza, permitiu a aquisição de conhecimentos fundamentais para o posterior cultivo das diversas variedades de plantas. As trocas de sementes e informações realizadas entre grupos camponeses é um processo de partilha que lhes permitiu aumentar a diversidade genética das variedades por eles cultivadas, dedicado à agrobiodiversidade e agroecossistemas.

Desta forma, as sementes crioulas caracterizam-se como sementes da biodiversidade, pois são um patrimônio essencial, que representam características naturais e culturais de uma sociedade, sendo moldadas através de um processo consciente de escolha, realizado pelos agricultores, representando seu modo de vida (PEREIRA, DAL SOGLIO, 2020).

É importante destacar que não sofreram modificações genéticas por meio de técnicas, como de melhoramento genético, mas através do manejo desenvolvido por comunidades tradicionais e agricultores familiares, agricultura orgânica e sustentável, pois contribui para que o meio ambiente fique em equilíbrio tanto com relação ao ecossistema como em relação à saúde do ser humano, eis que respeita o tempo da natureza, retirando somente o que a natureza é capaz de repor e não faz uso de agrotóxicos, como fertilizantes artificiais, pesticidas e reguladores de crescimento e aditivos para os animais, utilizando apenas de técnicas mecânicas, como barreiras naturais, capinas, controle biológico para amenizar o ataque de pragas e doenças (PEREIRA, DAL SOGLIO, 2020).

A lei de sementes nacional, conforme anteriormente exposto, privilegia as sementes híbridas, as sementes transgênicas. Porém, um grande avanço é o reconhecimento dos cultivares locais, através do art. 48, que dispõe:

Art. 48. Observadas as demais exigências desta Lei, é vedado o estabelecimento de restrições à inclusão de sementes e mudas de cultivar local, tradicional ou crioula em programas de financiamento ou em programas públicos de distribuição ou troca de sementes, desenvolvidos junto a agricultores familiares.

Desta forma, fica expressamente vedada a restrição de qualquer variedade local em programas de financiamento ou políticas públicas de distribuição ou troca de sementes, voltados para a agricultura familiar, facilitando o apoio de organizações civis e o desenvolvimento de políticas públicas. 
É importante destacar que, mesmo com este reconhecimento, ainda fica a critério do Ministério da Agricultura o reconhecimento e definição das variedades locais como tais e se estas se diferenciam das variedades comerciais, sendo necessária a observância de "descritores socioculturais e ambientais" no processo. O Ministério deve, portanto, consultar e prever a participação dos agricultores locais neste procedimento, pois os mesmos são responsáveis pelos métodos e sistemas de manejo para melhoramento e adaptação das sementes.

Outros mecanismos jurídicos importantes para a proteção da agricultura tradicional são as Portarias no 58/2006 e no 51/2007 do Ministério do Desenvolvimento Agrário que criou, através da primeira, um cadastro nacional de cultivares locais, tradicionais ou crioulos, vinculados à Secretaria de Agricultura Familiar com a Portaria de 2007, em seu art. $3^{\circ}$, ampliando e tornando permanente este cadastro e estabelecendo critérios ${ }^{3}$ para o registro dos cultivares, tais como a necessidade de produção e desenvolvimento por agricultores familiares, assentados da reforma agrária e comunidades tradicionais e indígenas que neles reconheçam características fenotípicas bem determinadas, não envolvendo processos de hibridação e transgenes (manipulação genética em laboratório) ou qualquer outro desenvolvimento industrial e estejam em uso há mais de três anos.

São importantes medidas porque não apenas delimitam e registram as cultivares, facilitando o acesso a seguros agrícolas, mas também por identificar e reconhecer o trabalho dos agricultores e fornecer informações para políticas públicas que os auxiliem. Outro fator importante é o reconhecimento da natureza socioambiental e cultural dessas variedades ${ }^{4}$,

\footnotetext{
${ }^{3}$ Art. $3^{\circ}$ Poderá ser cadastrada cultivar local, tradicional ou crioula, assim entendida variedade que, cumulativamente:

I - tenha sido desenvolvida, adaptada ou produzida por agricultores familiares, assentados da reforma agrária, povos e comunidades tradicionais ou indígenas;

II - tenha características fenotípicas bem determinadas e reconhecidas pelas respectivas comunidades;

III - esteja em utilização pelos agricultores em uma dessas comunidades há mais de três anos;

IV - não seja oriunda de manipulação por engenharia genética nem outros processos de desenvolvimento industrial ou manipulação em laboratório, não contenha transgenes e não envolva processos de hibridação que não estejam sob domínio das comunidades locais de agricultores familiares.

${ }^{4} \S 1^{\circ}$ Pela sua própria natureza e tradição histórica, as cultivares locais, tradicionais ou crioulas constituem patrimônio sócio-cultural das comunidades, não sendo aplicável patente, propriedade e nenhuma forma de proteção particular para indivíduos, empresas ou entidades.

$\S 2^{\circ} \mathrm{O}$ cadastro não confere à entidade direito de propriedade ou posse à cultivar por ela cadastrada nem prerrogativa de detentora da cultivar, nem concede nenhum tipo de direito a nenhuma pessoa física ou jurídica.
} 
vedando expressamente qualquer tipo de apropriação individual ou proteção particular a estas que, mesmo registradas, não pertencerão a nenhuma entidade, pública ou privada.

A Política Nacional da Agroecologia e Produtos Orgânicos - PNAPO, instituída pelo Decreto $\mathrm{n}^{\circ} 7.794$, de 20 de agosto de 2012, reconhece a existência das sementes crioulas como variedades locais. Por outro lado, permite a comercialização dessas sementes, e não a troca, tal como estava previsto. Mesmo assim, o fato de reconhecerem as sementes é uma conquista, pois além de permitir debater o significado da semente crioula para as comunidades agrícolas, ajuda os agricultores a obterem incentivos dos bancos e instituições públicas para investir lavouras de sementes crioulas (GASPARINI, 2014).

Nesse contexto, importante é observar a necessidade de discussão acerca da efetivação dos diretos dos agricultores, amplamente afetados pelas imposições privacionistas da propriedade intelectual das transnacionais e as iniciativas e propostas de organizações civis e políticas públicas voltadas para a distribuição das variedades de sementes locais.

A partir da primeira metade da década de 90, as contradições existentes entre os direitos de propriedade intelectual, instituídos por Tratados Internacionais (influenciando a legislação brasileira) e as práticas consuetudinárias da agricultura tradicional tornam-se mais evidentes, com diversas organizações da sociedade civil questionando os dispositivos legais que buscavam aplicar os mecanismos de propriedade intelectual a diferentes formas de vida. O sistema de propriedade intelectual baseia-se em sistemas de conhecimento, valores e práticas muitos distintos em relação aos conhecimentos tradicionais, no que diz respeito à biodiversidade.

O conceito de direito dos agricultores foi desenvolvido por Pat Mooney e Cary Fowler, da antiga organização governamental Rafi (Rural Advancement Foundation Internation), atualmente ETC (Erosion, Technology and Concentration), nos anos 1980, sendo incorporado a muitos instrumentos internacionais em oposição aos "direitos dos melhoristas", assegurados através de diferentes instrumentos jurídicos vigentes em nível nacional e internacional (SANTILLI, 2009).

Apesar da sua implementação em diversos documentos jurídico-internacionais, não houve consenso sobre o significado, a extensão de seu conteúdo e a forma de efetivação dos direitos dos agricultores. Ademais, as motivações para a proteção dos direito dos agricultores tiveram várias abordagens distintas, gerando divergências durante as discussões acerca do Tratado Internacional sobre o tema, destacando-se algumas (SANTILLI, 2009). 
A primeira diz respeito ao reconhecimento dos direitos como uma "recompensa" dos agricultores por sua contribuição para a conservação da agrobiodiversidade, o que seria uma obrigação moral eis que o sistema de propriedade intelectual os ignorava completamente, mesmo quando a inovação produzida somente foi possível graças a um conhecimento tradicional acumulado por diversas gerações de agricultores.

A segunda seria o reconhecimento do direito dos agricultores como promoção da conservação e dos conhecimentos tradicionais e da agrobiodiversidade como forma de garantir a segurança alimentar, beneficiando não apenas esta categoria, mas toda a humanidade. É uma visão utilitarista que ignora a necessidade de autossuficiência e melhoria da qualidade de vida dos agricultores tradicionais, que são os responsáveis pela base alimentar de uma boa parcela da população mundial.

A terceira enxerga este direito como garantia de que o direito dos melhoristas não inviabilizasse as práticas agrícolas locais, o que resumiria todo o direito ao "privilégio do agricultor" de não pagar royalties ao utilizar determinadas variedades protegidas sem a autorização do melhorista.

A quarta, por fim, seria apenas um reconhecimento formal das práticas agrícolas tradicionais, que já são utilizadas e recorrentemente adotadas desde os primórdios da agricultura. Ressalta-se que todas as vertentes, motivações e formas de implementação desses direitos foram discutidas, sendo alguns pontos incluídos no Tratado e outros não (SANTILLI, 2009).

No plano internacional, os direitos de agricultores (farmers' rights), são definidos como "direitos resultantes de contribuições passadas, presentes e futuras, dos agricultores para a conservação, o desenvolvimento e a guarda de recursos genéticos vegetais, particularmente aqueles nos centros de origem/diversidade", conforme disposição do Tratado Internacional de Recursos Fitogenéticos para Alimentação e Agricultura (TIRFAA), da FAO (SANTILLI, 2005).

Nota-se que o Preâmbulo do Decreto 6.476/08 (que promulgou o Tratado) trata de forma expressa os direitos de guardar, usar, trocar e vender sementes, afirma que "Nada no presente Artigo será interpretado no sentido de limitar qualquer direito que os agricultores tenham de conservar, usar, trocar e vender sementes ou material de propagação conservado nas propriedades, conforme o caso e sujeito às leis nacionais". 
O Tratado destaca a importante contribuição dos agricultores à conservação dos recursos genéticos utilizados na agricultura e alimentação e reconhece seu direito de conservar, utilizar, intercambiar e vender sementes e outros materiais de propagação conservados em suas unidades produtivas ou em territórios de uso comum, participando das decisões e da distribuição justa e eqüitativa dos benefícios gerados pela biodiversidade ali manejada.

Tal direito é bastante controverso, pois contraria restrições impostas pela Ata de 91 da Convenção da UPOV, que influenciou diversas legislações agrárias e as leis de sementes. No Brasil, a já citada Lei de Proteção de Cultivares, em que pese abrir algumas brechas para a troca e doação entre si de sementes aos pequenos produtores rurais, não permite a venda de sementes de variedades protegidas sem a autorização do titular e pagamento de royalties, mesmo nos mercados locais e entre os próprios tradicionais.

Tal restrição configura uma clara violação do direito de usar, trocar e vender sementes, afeta a agrobiodiversidade e é um exemplo de como a legislação interna ainda precisa se adequar às normas internacionais, eis que ainda privilegiam as variedades melhoradas por "profissionais da agricultura", em detrimento das variedades crioulas.

Para que seja possível a efetivação dos direitos dos agricultores, é necessário o debate acerca da proteção jurídica do seu conhecimento e a repartição justa e equitativa dos benefícios que estes geram. Diversas propostas foram feitas por legisladores, ativistas e organizações governamentais e não governamentais, sendo de muita importância as iniciativas de empreendedorismo social, conjugadas entre a sociedade civil, as universidades, o poder público e a iniciativa privada, como os bancos de semente, onde o conhecimento tradicional dos coletores é utilizado no aperfeiçoamento e armazenamento de sementes naturais, tradicionais, que serão utilizadas para atender as necessidades do mercado local.

\section{CONSIDERAÇÕES FINAIS}

O problema da falta de discussão e debate acerca da importância da proteção da agrobiodiversidade da agricultura tradicional em contraposição a homogeneidade da agricultura industrial é demonstrado pela falta de participação dos agricultores nas principais leis e políticas públicas sobre acesso a recursos genéticos e repartição de benefícios. $\mathrm{O}$ trabalho procurou abordar, em uma sequência lógica, os assuntos que compreendem o tema, debatendo-se acerca do mercado de sementes, sua relação com a propriedade intelectual e a 
necessidade de expansão da utilização da agricultura baseada no conhecimento tradicional para a proteção da segurança alimentar, através do estimulo às características socioculturais dos agricultores que mais contribuem com o desenvolvimento sustentável.

Ao fim, chega-se à conclusão de que existe uma grande necessidade de políticas públicas que mantenham o agricultor em sua terra, sem que seja obrigado a abrir mão de seus saberes e recursos agrícolas tradicionais, como forma de estímulo à segurança alimentar e à conservação da biodiversidade.

Ao escolher o tema abordado neste trabalho, teve-se em mente o uso indiscriminado da ciência pelo mercado que resultou na possibilidade fática da manipulação e da apropriação da natureza, encontrando respaldo jurídico no Direito clássico de propriedade, tornando-se um instrumento legalizador que põe em causa o equilíbrio ambiental e social. Em razão deste quadro pessimista onde a cultura, o meio ambiente e até mesmo a vida se banalizam em frente aos interesses das empresas transnacionais de biotecnologia, é necessária a proteção e regulação de direitos à titularidade e posse (coletiva) dos recursos genético aos agricultores e povos tradicionais, sempre associados a critérios socioculturais.

Dessa forma, esses grupos também devem ter direito à ter benefícios (nem sempre monetários) tal qual as grandes indústrias farmacêuticas e químicas, pois ao emprestar seu conhecimento adquirido sobre o manejo de recursos fitogenéticos, revelando suas possíveis aplicações, descrevendo a utilização cotidiana em sua comunidade destes recursos naturais, auxiliam e poupam tempo e dinheiro no investimento de novas técnicas de beneficiamento e industrialização das propriedades dos recursos da agrobiodiversidade.

Permitir a monopolização das patentes, das sementes e da alimentação humana é estimular que poucos detenham o conhecimento e a capacidade de definir o que, como e onde será produzido o alimento para toda a humanidade, serão, direta ou indiretamente, permitindo que esse domínio seja exercido através da engenharia genética, gerando graves problemas de biossegurança, pois o modelo atual de agronegócio demanda na utilização de grandes populações homogêneas diminuindo número de variedades cultivadas e limitando a diversidade genética, o que, além de permitir o aparecimento de superpragas, pode acarretar a pobreza nutricional dos países que se submetem suas terras de maneira direta a este modelo.

No futuro, medidas legislativas mais protetivas devem ser tomadas, através da participação política dos agricultores familiares tradicionais e agroecológicos que vão não apenas a participação em conselhos, mas na efetivação de todas as decisões políticas que 
produzem impactos sobre os sistemas agrícolas locais e outros recursos fitogenéticos destinados à alimentação e agricultura. A Lei de Sementes deve ter sua regulação restrita a regular os sistemas formais, excluindo os sistemas locais, pois sua realidade sociocultural e econômica não os permite terem as mesmas exigências das grandes empresas.

Quanto as Leis atuais que tratam do direito dos agricultores de conservar, usar, trocar e vender sementes ou outros materiais de propagação, não deve haver impedimentos ou restrições legais inadequadas às características dos processos produtivos locais, mas a livre circulação, inclusive através da venda de sementes protegidas para outros agricultores familiares tradicionais e agroecológicos, desde que inclusos nos mercados locais.

Assim é justo porque se efetivamente considera a conservação da diversidade de espécies, variedades e agroecossistemas como um dos serviços ambientais prestados pelos agricultores, que devem possuir uma forma adequada de remuneração, assim como ter garantido o acesso (em condições facilitadas) de seus produtos da agrobiodiversidade ao mercado, o que contribuiria para a manutenção da segurança alimentar de todos os brasileiros, seja no meio rural ou urbano.

Mesmo diante de alguns avanços legislativos no que concerne ao reconhecimento da importância do agricultor tradicional e da agroecologia para o desenvolvimento de uma agricultura sustentável e orgânica, que permita a autossuficiência das comunidades familiares e uma melhor qualidade do alimento disponível para as pessoas no meio urbano, ainda predomina a realidade do modelo do agronegócio monocultor.

É necessária, portanto, uma reavaliação do papel do meio agrário para a qualidade de vida da população brasileira, sendo necessário expor que a opção por modelos econômicos produtivos, que garantam ao homem progresso, preservação e relações sociais efetivas, pode se satisfazer através de modelos alternativos, na agroecologia ou em outros modelos que não o tradicional, cuja tecnologia, capital e forma monocultural dita as regras, normalmente ignorando o papel dos agricultores para o prática de uma agricultura sustentável.

\section{REFERÊNCIAS}

BRASIL. Presidência da República. Política Nacional de Agroecologia e Produção Orgânica Decreto $\mathbf{n}^{\mathbf{0}}$ 7.794. Brasília: 2012. Disponível em < http://www.planalto.gov.br/ccivil_03/_ato2011-2014/2012/decreto/d7794.htm> Acesso em 14 de Fev. 2021. 
BRASIL. Presidência da República. Lei n. 10.711. Brasília: 2003. Disponível em<http://www.planalto.gov.br/ccivil_03/leis/2003/L10.711.htm>Acesso em 02 de Fev. 2021.

COMEGNA, Maria Angela. Desafios à conservação das sementes crioulas, p. 1-388-416. IN GOMES, Ingrid Aparecida. A produção do conhecimento geográfico 3. Ponta Grossa (PR): Atena Editora, 2018.

GASPARINI, Bruno. A apropriação genética da agrobiodiversidade enquanto estratégia biopolítica dos impérios alimentares no contexto da resolução biotecnológica. 322 p. Tese - UFPR. Curitiba, 2014.

LACEY, Hugh. As sementes e o conhecimento que elas incorporam. São Paulo em Perspectiva, v. 14, n. 3, p. 53-59, 2000.

MANIGLIA, E. As interfaces do direito agrário e dos direitos humanos e a segurança alimentar São Paulo: Editora UNESP; São Paulo: Cultura Acadêmica, 2009.

PEREIRA, Viviane Camejo; DAL SOGLIO, Fabio Kessler. A Conservação das sementes crioulas: uma visão interdisciplinar da agrobiodiversidade. Editora UFGRS, 2020.

PESSANHA, Lavínia Davis Rangel. Transgênicos, recursos genéticos e segurança alimentar: uma análise da judicialização do conflito sobre a liberação da soja RR no Brasil. Vol. IX/2002 da Revista Cadernos de Debate, p. 69-92. Unicamp. Campinas, 2002.

SANTILLI, Juliana. Socioambientalismo e novos direitos: proteção jurídica à diversidade biológica e cultural. São Paulo: Peirópolis, 2005.

2009.

Agrobiodiversidade e direitos dos agricultores. São Paulo. Peirópolis,

WANDSCHEER, Clarissa Bueno. Patentes e conhecimento tradicional: uma abordagem socioambiental da proteção jurídica do conhecimento tradicional. Juruá Editora, 2004. 